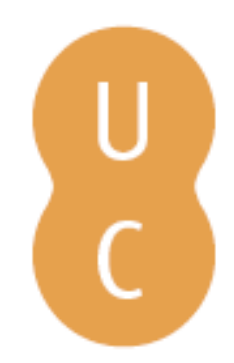

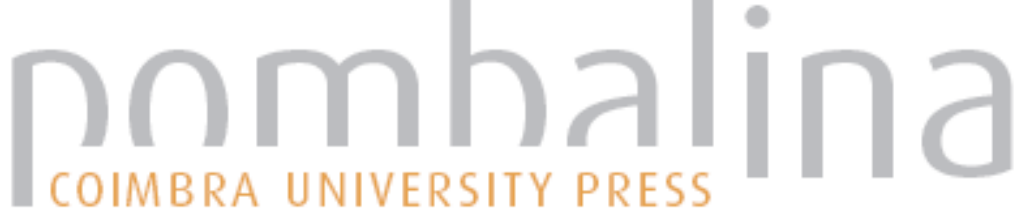

\section{A Timeless Legacy: the Calendars of Ancient Egypt}

Autor(es): $\quad$ Canhão, Telo Ferreira

Edições Afrontamento; CITCEM - Centro de Investigação

Publicado por: Transdisciplinar «Cultura, Espaço e Memória»; Centro de Estudos

Clássicos e Humanísticos; Alexandria University; Imprensa da

Universidade de Coimbra

URL

persistente:

URI:http://hdl.handle.net/10316.2/36186

DOI:

DOI:http://dx.doi.org/10.14195/978-989-26-0966-9_20

Accessed : $\quad$ 26-Apr-2023 14:56:27

A navegação consulta e descarregamento dos títulos inseridos nas Bibliotecas Digitais UC Digitalis, UC Pombalina e UC Impactum, pressupõem a aceitação plena e sem reservas dos Termos e Condições de Uso destas Bibliotecas Digitais, disponíveis em https://digitalis.uc.pt/pt-pt/termos.

Conforme exposto nos referidos Termos e Condições de Uso, o descarregamento de títulos de acesso restrito requer uma licença válida de autorização devendo o utilizador aceder ao(s) documento(s) a partir de um endereço de IP da instituição detentora da supramencionada licença.

Ao utilizador é apenas permitido o descarregamento para uso pessoal, pelo que o emprego do(s) título(s) descarregado(s) para outro fim, designadamente comercial, carece de autorização do respetivo autor ou editor da obra.

Na medida em que todas as obras da UC Digitalis se encontram protegidas pelo Código do Direito de Autor e Direitos Conexos e demais legislação aplicável, toda a cópia, parcial ou total, deste documento, nos casos em que é legalmente admitida, deverá conter ou fazer-se acompanhar por este aviso. 


\title{
A TIMELESS LEGACY: THE CALENDARS OF ANCIENT EGYPT
}

\author{
TELO FERREIRA CANHÃO
}

Centro de História (University of Lisbon).

\begin{abstract}
Since the year 45 B.C., Julius Caesar introduced, in the whole Roman world, the Egyptian calendar with 365 days and six hours i.e. 365, 25, adding the necessary days in the shorter months. It was also intercalated one day between the 23rd and the 24th of February every four years, which was called bissextile because the 6th day before the calends of March counted twice. This day gave the name to the year where it was included but it was not the 29th of February, which did not exist at the time. This calendar became known as the Julian calendar and lasted until the 1st of January 1582 when Pope Gregory VIII made its last modification, implementing what we know as Gregorian calendar, which has been in use till the present day. The adopted Egyptian calendar had a mathematical simplicity; it didn't require any adjustments by means of intercalary days or months and was used to date every official or officious act, thus justifying Julius Caesar's statement: «the only intelligent calendar of Mankind's history». He had for advisor an Egyptian hemerologist, the astronomer Sosigenes from Alexandria, an Egyptian about whom we know little but who managed to impose his ideas about this issue to Julius Caesar not only because they were good but also because they were based on a millennial practice.
\end{abstract}

In the 1st century B.C., Alexandria was the most crowded urban area of the Ancient World, except for Rome. A myriad of races and cultures coming from the Greek world, Rome, Persia, Arabia, including a large Jewish community joined the indigenous popula- 
tion of Egyptians and Nubians. There, the late Hellenistic culture flourished. It was through Alexandria that Egypt has opened itself to the Mediterranean world. In that same century Roman's civil year was three months in advance in relation to the solar year thus showing the ancestral imperfection of the Roman calendar. After being sworn as Pontifex Maximus, Julius Caesar (100-40 B.C.) solved the problem, by adding the days required to set the dates. For that reason the year 46 B.C. excepcionally got 445 days, corresponding to the year 708 after the foundation of the city of Rome and it must have been the ultimus annus confusionis, according to the writings of Macrobius, a Roman writer of the beginning of the 5th century, in his book Saturnais ${ }^{1}$.

From 45 B.C. on, the Romans adopted the Egyptian solar calendar of 365 days and six hours, adding the required extra days to the shorter months. They also inserted one day between February 23 and 24, every four years, which was called bissextile, since the sixth day before the calends of March was counted twice. This day gave the name to the year in which it was included, but it wasn't February 29 yet, because it didn't exist at the time. This calendar became known as the Julian calendar and it was used until January 1, 1582, when Pope Gregory XII made its last major reform, thus implementing the Gregorian calendar, as we know it, and which is now still in use.

The Egyptian calendar, which Julius Caesar had installed upon the whole Roman world, was of a great mathematical simplicity. It didn't require any adjustments by inserting days or months and was used to date any official or officious act, religious or civil, leading to Julius Caesar's statement «the only intelligent calendar that has ever existed in the History of Man $»^{2}$. On this matter, he was accessorized by the Egyptian hemerologist Sosigenes of Alexandria, an Egyptian about whom little is known but who managed to impose all his ideas to Julius Caesar, since they were based on a millennial practice which had already proved to be actually good.

\section{THE RECKONING OF TIME IN ANCIENT EGYPT}

The Egyptian conception of time derived from the fusion of two complementary ideas:: djet, a linear counting of times - which started whenever a new king ascended to the throne, one after the other in an irreversible way - it was linked to earthly items and to the ideas of lasting duration; and neheh - the cyclic time grounded on the periodicity of cosmic phenomena, particularly the movement of the sun, which reborns every day - it was linked to the ideas of «rebirth», «transformation», «becoming». The conception of History itself, in ancient Egypt, was a «celebration» of the eternal return to the «first time», the time when

\footnotetext{
${ }^{1}$ SANTOS, 2006: 120.

${ }^{2}$ POSENER, 1970: 40.
} 
the Creator established the essential order, which the pharaoh was supposed to maintain. According to the myth of Osiris, the dead king was taken as a new Osiris, getting into eternity (neheh) forever (djet), two concepts that, by appearing together, express the idea of «forever and ever». This is the perfect coexistence of two different concepts created by the gods: a cyclic time, marked by traditions and religious rituals, and so related to the sacred; and a more linear time, marked by daily activities and, therefore, profane. The union of these two concepts stood for the wholeness of time ${ }^{3}$.

The 365-day-years were counted from the day when the king ascended the throne, thus following a linear reckoning of time until the moment of his death. With the next king the counting restarted from the beginning. The number 365 had been originally calculated, in pre-dynastic times or before the end of the Neolithic, in one of two ways: either by calculating the average of the systematic recording of the days imposed by lunar observation, or then by observing the interval between two appearances of a reference star, which, as we will see, should be Sirius.

This counting didn't depend on the seasons of the solar year, which were three and had a precise existence marked exclusively by the needs of agriculture:

- Akhet (the inundation itself, which, according to the Julian calendar, went from mid-July to mid-November, more precisely from July 19 to November 14 - the dates we match to the Gregorian calendar are only approximate, since they depended on variable astronomical phenomena - and could be called a season of floods);

- Peret (the period of the spring waters and the growing of plants, from mid-November to mid-March, more precisely from November 15 to March 14, or the spring time);

- Shemu (the period of drought and crop, from mid-March to mid-July, more accurately, from March 15 to July 13, or the harvest time).

Each season had four months of thirty days each (numbered 1 to 30), 360 days in total, to which were added five days - the Greeks called them epagomenal days and the Egyptians called them heru renepet, «those which are above the year» - considered out of the year and numbered from 1 to 5 , a total of 365 days at the end of which was celebrated «The opening-of-the-Year», that is, the New Year's Day. On each of the five epagomenal days it was celebrated the birth, respectively, of Osiris (mesut Usir, July 14), Horus (mesut Hor, 15 July), Seth (mesut Set, 16 July), Isis (mesut Iset, July 17) and Nephthys (mesut Nebet-hut, July 18) the five deities who, in Heliopolitan theology represented time. On the other hand, on the first day of the year, July 19, it was celebrated the «birth of Re», mesut $R e^{4}$. As a result of con-

${ }^{3}$ CANHÃO, 2006: 39.

${ }^{4}$ CANHÃO, 2006: 40. 
cerns about agriculture, the most ancient Egyptian calendar was based on lunar observations combined with the annual cycle of flooding of the Nile, measured by especial devices known as Nilometers.

Each month was assigned a name, usually the name of the festival that was held at that time and, simultaneously, the name of the celebrated deity. This is attested to the Middle Kingdom, in the region of Memphis:

- the 1st month of the Flood was called Tekhi; the 2nd, Menekhet; the 3rd, Khenethuthor; the 4th, Nehebkau;

- the 1st month of winter (5th month), Shefbedet; the 2nd (6th month) Rekehaá; the 3rd (7th month), Rekehnedjés; the 4th (8th month), Renenutet;

- the 1st month of summer (9th month), Khonsu; the 2nd (10th month), Khenetkhetyperetj; the 3rd (11th month), Ipethemet and the 4th (12th month) Upetrenpet $^{5}$.

In the New Kingdom, the majority of these designations have changed, especially due to the supremacy of the festivals held at Thebes. Reinforced by the theophoric nomenclature $^{6}$, the Egyptian designations of the months have survived in Greek language and are still in use by the Coptic Church in its religious calendar. The new designations were (in brackets the Greek name):

- the 1st month of Akhet was Djehuti (Thoth), the 2nd was Paneipet (Paofi), the 3rd was Huthor (Athir) and the 4th was Kahorka (Khoiak);

- the first month of Peret was Taabet (Tibi), the 2nd was Panepame-kheru (Meshir), the 3rd was Paneamen-hotep (Famenoth) and the 4th was Panerenenutet (Farmuti);

- the first month of Shemu was Panekhensu (Pakhonsu), the 2nd was Paneinet (Paini), the 3rd was Ipip (Epifi) and the 4 th was Mesutré (Mesori) ${ }^{7}$. Depending on the sources, there are variants for some of these names.

The names of the months appeared mostly in lists of festivals or in private letters, but rarely in ordinary texts. The dating of a particular event followed a standard procedure: «Year 6 (ie, number of years of reign), 2 winter 12 (ie, the second month of the season of Peret, Panepamekheru, day 12), under the majesty of the King of Upper and Lower Egypt (throne-name of the reigning pharaoh)» ${ }^{8}$.

\footnotetext{
${ }^{5}$ ALLEN, 2000: 108.

${ }^{6}$ This became a common practice in Egypt to form the names of individuals.

${ }^{7}$ ALLEN, 2000: 108; DEPUYDT, 1997: 129.

${ }^{8}$ It is thought to have been common the designations of the months in spoken Egyptian, as we use today January for «month one», February for «month two», March for «month three», etc.
} 
There is also a variation in relation to the positioning of epagomenal days. Although the last day of the year is always the 30th day of Mesutré, and the five epagomenal days are beyond the year, in the Old Kingdom they preceded the year, while in the Middle and New Kingdom they were placed at the end of the year.

The natural division of the lunar month into irregular quarters still originates an irregular composition of months in what concerns the number of days assigned to each month. In the early Egyptian civilization it was the very week with seven and eight days that alternated in accordance with the lunar phases, but this system was soon replaced by the introduction of a much more regular one: the Egyptian month of three decades, each marked by the appearance of a decan. The Egyptian decans are stars that seemed to born, live and die, so they were known as «the living» (ankhu), as opposed to the circumpolar stars «those who do not know the destruction» (ikhemu-sek). In the decanal cycle the full circle of each decan was $360^{\circ}$. They were 36 and, due to translational movement of the Earth, were visible for periods of ten days, hence their name ${ }^{9}$ (Fig. 1). So, the year was divided into 36 periods of ten days and each month into three decades. Although the word «week» was unknown to the Egyptians, every decade corresponded, in current terms, to a «week» of ten days. The gap of five days between the last and first decan of this decimal organization was completed by epagomenal days, out of the decanal cycle (36 days $\mathrm{x} 10=360$ days, or 12 months $\mathrm{x} 30$ days $=360$ days, or 3 seasons $\mathrm{x}$ 120 days $=360$ days) and, as such, treated after 36 decades, only then completing the year of 365 days.

The decanal system would lead the Egyptians to divide the day into twenty-four hours (unut),

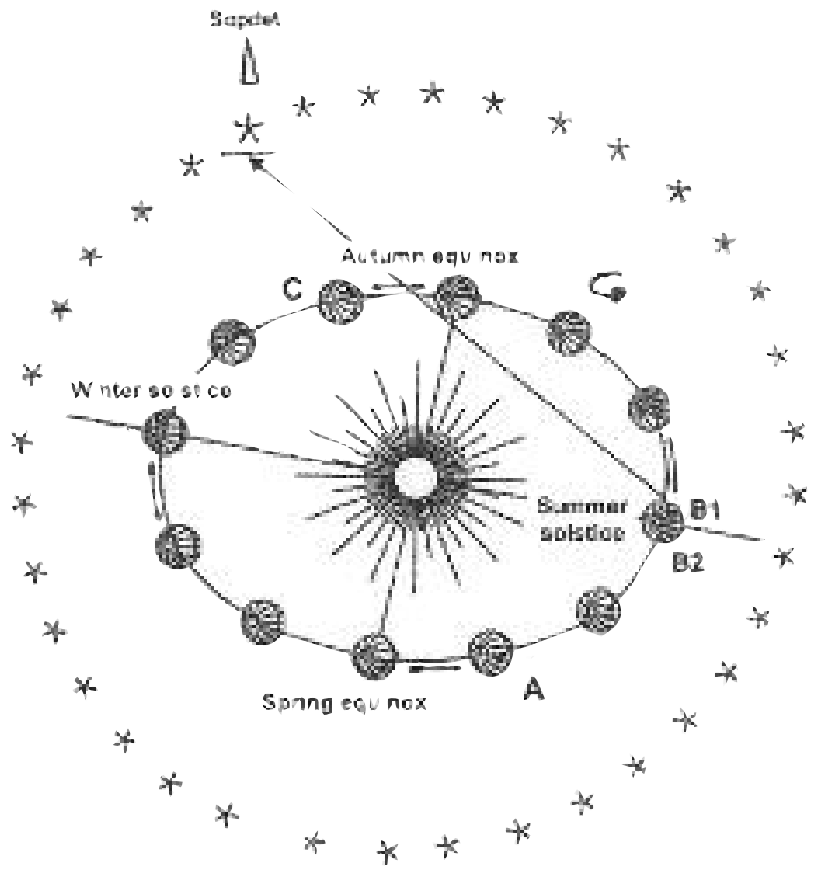

Fig. 1: Rotation: the 36 decanal stars of the year. Every ten days of the translational movement of the Earth, a new star appears. When the Earth is on A, only the stars outside the orbit of the earth can be seen. The Sun prevents us from seeing Sirius. It is its period of invisibility. An observer on B2 (beginning of the night) can't see Sirius because the Earth is in-between; but on B1 (end of night) Sirius can be seen straight before dawn: the heliacal rising of Sirius. On C, Sirius remains visible all night.

\footnotetext{
${ }^{9}$ SAUNERON, 1970: 80.
} 
each of them equal to $1 / 24$ of the day, of sixty minutes each ${ }^{10}$, with twelve night hours, the «hours of darkness», and twelve daytime hours, the "hours of sun», with reference to the sun at its zenith. The day was divided into ten hours according to the movement of the sun, plus two of twilight - sunrise and sunset. The fact that in summer, at the latitude of Egypt, only twelve decans could be seen each night rising from darkness (Fig. 5) led to the division of the night into twelve «hours». At night the system worked as follows: decan I rose early in the evening of July 19 and when it went out of sight it was signaled the end of that night, and the same happened in the next nine nights. It was then replaced in that role by decan II for another ten days. After the same number of days it was replaced by decan III and so on until getting to decan XXXVI. In each $1 / 24$ of the day, the next decan entered, waiting for its decade of «control». Thus, the stellar clocks were organized in frames of thirty-six columns and twelve rows, giving for each decade (columns) and each hour of the night (lines) the decan whose rising marked the end of that hour. The simplicity of the scheme got disturbed by the epagomenal days, to which were introduced other twelve intercalary decans. Each decan was moving regularly and diagonally upward from one decade to the next.

\begin{tabular}{|c|c|c|c|c|c|c|c|c|c|}
\hline Hours & 1 & 2 & 3 & 4 & ....Decans.... & 33 & 34 & 35 & 36 \\
\hline 1 & I & II & III & IV & $\ldots \ldots \ldots \ldots \ldots \ldots$ & XXXIII & XXXIV & $X X X V$ & XXXVI \\
\hline 2 & II & III & IV & V & $\ldots \ldots \ldots \ldots \ldots \ldots$ & XXXIV & $X X X V$ & XXXVI & I \\
\hline 3 & III & IV & V & VI & ……… & $X X X V$ & $\mathrm{XXXVI}$ & 1 & II \\
\hline 4 & IV & V & VI & VII & ……… & XXXVI & I & II & III \\
\hline 5 & V & $\mathrm{VI}$ & VII & VIII & ………... & I & II & III & IV \\
\hline 6 & VI & VII & VIII & IX & ............... & II & III & IV & V \\
\hline 7 & VII & VIII & IX & $X$ & $\ldots \ldots \ldots \ldots \ldots \ldots$ & III & IV & V & VI \\
\hline 8 & VIII & IX & $x$ & XI & $\ldots$. & IV & V & VI & VII \\
\hline 9 & IX & $x$ & $X I$ & XII & ............ & V & VI & VII & VIII \\
\hline 10 & $x$ & XI & XII & XIII & n.............. & VI & VII & VIII & IX \\
\hline 11 & $X I$ & XII & XIII & XIV & $\ldots \ldots \ldots \ldots \ldots \ldots$ & VII & VIII & IX & $x$ \\
\hline 12 & XII & XIII & XIV & $\mathrm{XV}$ & $\ldots \ldots \ldots \ldots \ldots \ldots$ & VIII & IX & $\mathrm{X}$ & $X I$ \\
\hline
\end{tabular}

Each hour corresponded to a divine couple and a name, used mainly in astronomical texts. For example, they designated the first hour of the day ubenut, "the bright one», the last night of peter neferu neb set, "the one which sees the beauty of Re», the sixth hour of the day, midday, ahat, "the one that is standing», expressing the verticality of the shadow. However, in current texts, the hours were designated by counting the ordinal numbers. For example: unut mehet-10 net heru is «the tenth hour of the day» (four in the afternoon) or

\footnotetext{
${ }^{10}$ BRIER, HOBBS, 1999: 77.
} 
unut 4-nut net gereh the "fourth hour of the night» (ten o'clock). The division of the day and night into twelve hours each, seems originally Egyptian and may have to do with the practical need to maintain over the years equinoctial equality between day and night, combined with mythological issues, the twelve territories of the Duat that Re followed on his night trip, for example, or even, by analogy with the twelve months in which the year is divided.

However, the division of the hour into sixty minutes was introduced by the Babylonians who used the sexagesimal system (60 is divisible by 30, 20, 15, 12, 10, 6, 5, 4, 3 and 2) created by the Sumerians, the first to cultivate astronomy and to apply mathematical methods to it, and which we still use for measuring time. The day was divided into twelve double hours, while each hour was divided into sixty double minutes and the minute into sixty double seconds. Although the division of minutes in 60 seconds has not been achieved by the Egyptians, they had the notion that the minute was still a very wide measure of time for certain circumstances, once they recognized as the smallest unit of time the at, usually translated by «moment», «instant», and without a definite duration ${ }^{11}$. Besides the designations used in religious and astronomical contexts, there were popular names for the hours, in which certain expressions corresponded to numbers, for the hours of day or night, such as: em duá, «in the morning»; nu en seti-rá, «the hour of perfume for the mouth», i.e., the time of the noon meal; mesit, "supper», "the last meal of the day», er ter en khani, "at the time of night».

The day began with sunrise, with various devices to measure the hours. By day it was used the sundial, which the Greeks and Romans called the gnomon, literally the «indicator». It was a simple sundial which measured the length or direction of a shadow, produced by a stick and projected horizontally, vertically or obliquely in a graduated flat or curved surface. Since sundials could not be used at night, the decans were used to determine the twelve night hours. From this observation stellar clocks were used, the merkhet, «instrument of knowledge» (Fig. 6) and a sighting tool, a forked pole (Fig. 6), a kind of wire-plumb with a function similar to astrolabe ${ }^{12}$. The observation of the evolution of stars was reserved for priests in charge of measuring time, a kind of astronomers who systematically measured the height of the reference stars, made their recording in tables and compared them with previous ones $^{13}$. Although only approximately, they determined what time of the night they were. It was a systematic work, fortnightly, since the rotation and translation of the Earth determine the constant changes in the positioning of the stars.

From the New Kingdom on, a full star table was composed of twenty-four partial tables, two for each month - not considering epagomenal days. These fortnightly astro-

\footnotetext{
${ }^{11}$ SHAW, NICHOLSON, 1995: 58.

12 SALES, 2001: 121.

${ }^{13}$ RACHET, 1987: 45.
} 
nomical tables show the image of a man kneeling on the floor, his face facing the viewer and the body surrounded by stars arranged in a grid background composed of nine vertical and thirteen horizontal lines (Fig. 6). This is a representation of one of two priests in charge of measuring time. Each drawing shows only one of these two astronomers who were facing each other along the direction from south to north, on the horizontal roof of a temple. There was a table where the position of reference stars in each hour of the night was registered as well as a device for astronomical vision, to observe the entrance of the stars represented on the board along a north-south line. Thus, any time of the night could be indicated. The observer indicated the position of a star in the sky, according to the position it occupied in relation to the silhouette of his partner: above the middle of the body, above the right elbow, above the right ear or right eye or possibly above the eye, ear or left elbow. This decanal transit was mentioned in the grid in seven internal vertical lines. There are beautiful decans lists, the most famous in the vaulted ceiling of the tomb of Seti I, organized in hourly and very complete tables, with their associated deities. It must be said, however, that because the tables of the royal tombs are mainly intended for decoration, the positioning of the stars next to the figures does not fully coincide, or is even at odds, with the indications of the respective table.

Regarding the example of Figure 6, the sixteenth day of month Paneipet (Paofi), the second month of Akhet, we have:

\begin{tabular}{|c|c|c|}
\hline 1st hour & leg of the Giant & above the middle \\
\hline 2nd hour & the pedestal star of the Giant & above the middle \\
\hline 3rd hour & Arit, the star & above the left eye \\
\hline 4th hour & the bird's head & above the left eye \\
\hline 5 th hour & its back & above in the middle \\
\hline 6th hour & the star of thousands & above the left eye \\
\hline 7th hour & Sart, the star & above the left eye \\
\hline 8th hour & the Orion arm & above the left eye \\
\hline 9th hour & Orion, the star & above the left elbow \\
\hline 10th hour & the star that follows Sothis & above the left elbow \\
\hline 11th hour & the star that precedes «two stars» & above the right elbow \\
\hline 2th hour & the water stars & above in the middle ${ }^{14}$ \\
\hline
\end{tabular}

Fifteen days later, on the first of Hathor, the third month of Akhet, the stars occupy the following positions in this new table:

\footnotetext{
${ }^{14}$ ERMAN, RANKE, 1976: 451.
} 


\begin{tabular}{|c|c|c|}
\hline 1st hour & the pedestal star of the Giant & above in the middle \\
\hline 2nd hour & Arit, the star & above the left eye \\
\hline 3rd hour & the bird's head & above the left eye \\
\hline 4th hour & its back & above in the middle \\
\hline 5 th hour & the star of thousands & above in the middle \\
\hline 6th hour & Sart, the star & above in the middle \\
\hline 7 th hour & the Orion arm & above in the middle \\
\hline 8th hour & Orion, the star & above the right eye \\
\hline 9th hour & the star that follows Sothis & above the right eye \\
\hline 10th hour & the star that precedes «two stars» & above in the middle \\
\hline 11th hour & the water stars & above in the middle \\
\hline 12th hour & the lion's head & above in the middle ${ }^{15}$ \\
\hline
\end{tabular}

After another fifteen days, on the sixteenth day of the same month of Hathor, the stars were arranged in another table this way:

$\begin{array}{lll}\begin{array}{l}\text { 1st hour } \\ \text { 2nd hour }\end{array} & \begin{array}{l}\text { Arit, the star } \\ \text { the bird's head }\end{array} & \begin{array}{l}\text { above the left eye } \\ \text { above in the middle }\end{array} \\ \text { ith hour } & \begin{array}{l}\text { its back } \\ \text { the star of thousands }\end{array} & \begin{array}{l}\text { above in the middle } \\ \text { above in the middle }\end{array} \\ \text { th hour } & \text { Sart, the star } & \text { above the right eye } \\ \text { 6th hour } & \text { the Orion arm } & \text { above in the middle } \\ \text { 7th hour } & \text { Orion, the star } & \text { above the left eye } \\ \text { 8th hour } & \text { the star that follows Sothis } & \text { above the left eye } \\ \text { 9th hour } & \text { the star that precedes «two stars» } & \text { above in the middle } \\ \text { 10th hour } & \text { the water stars } & \text { above in the middle } \\ \text { 11th hour } & \text { the lion's head } & \text { above in the middle } \\ \text { 12th hour } & \text { its tail } & \text { above in the middle }\end{array}$

In the New Kingdom another instrument was invented to measure time, whether day or night: the clepsydra or waterclock (Fig. 3). The oldest of them date from the 18th Dynasty. They were made of stone, copper or ceramic, of considerable size, with a time scale engraved on the inside, the exterior decorated with inscriptions and representations of time deities and a hole at the bottom to drain the water. Perhaps more to worship than for technical reasons, the Egyptians divided the unequal nights into twelve equal parts. In I In fact, with the exception of two annual equinoxes, all the other days and nights of the year have

\footnotetext{
${ }^{15}$ ERMAN, RANKE, 1976: 451.

${ }^{16}$ ERMAN, RANKE, 1976: 452.
} 
unequal lengths due to Earth's axial obliquity in relation to its orbit, which determines the seasons and causes short nights in summer and long nights in winter. Different marks inside the clepsydras determined the different lengths of the night hours according to the months and seasons of the year. The greater or lesser water flow velocity was obtained by varying the diameter of the hole through which the water passed. Thus, by keeping the same pace, it drained the twelve parts of each night. Probably, they changed the device according to the time of the year, since only clepsydras with one hole have survived to our day, which, according to the fragments of an inscription of Amenemhat, is an improvement of the waterclock of multiple holes. The inventor of this improved clepsydra not only recorded the fact that the king Amenhotep I considered it as «the most beautiful of all things», but also specifies that through its «excellent measuring vessel, the water flew only through a single hole» ${ }^{17}$. There are also depictions of clepsydras presenting simultaneously the summer sun and winter sun, the first being represented higher than the second. The use of different types of clock shows us that the Egyptians used alternately the time set by the decans, the equinoctial hour equal to the twenty-fourth part of the time of the rotation of the earth at the moment of equinoxes, and the solar hour, which varied in size according to the months of the year, graduating their different clocks accordingly.

\section{THE DUAL CALENDAR}

The Egyptians devaluated the lunar cycles and the mismatch between the counting of the days and the real revolution of the Sun (a solar year of 365.2422 days includes 12 lunar months of 354 days, since the moon takes 29 days and a half to return to the same phase $)^{18}$. But they weren't unaware of these issues and didn't ignore them. On the contrary, the solar year marked automatically the astronomical phenomena that governed their agricultural year, and keeping this in mind, the Egyptians celebrated another Opening-of-the-Year on the first day of each solar year, driven by royal enthronizations. This day was determined by the onset of the east brightest star in the sky, Sepedet, Sirius (gr. Seirios; lat. Sirius) belonging to the constellation Canis Major, and in Latin, commonly called Canicula, what happened systematically around July 19 of each year (peret sepedet), when the Nile water level rose $^{19}$. Seeing this as a good premonition, they saw in it the female deity Sopdet (the Greek Sothis), goddess of floods, whom they identified both with Satjet (or Satet), the protector of the region of the first waterfall, and with Isis, whose tears shed for Osiris swelled the Nile. The relationship established between the annual cycle and the life of the Nile and, conse-

\footnotetext{
${ }^{17}$ ERMAN, RANKE, 1976: 449-450.

${ }^{18}$ SAVOIE, 1988: 102; BOMHARD, 1999: 6.

${ }^{19}$ SHAW, NICHOLSON, 1995: 42.
} 
quently, the very survival of the Egyptians, led to the early realization that the eternal return of the flood coincided with the annual cycle of the star Sirius ${ }^{20}$.

Two calendars were thus in use: one based on the course of the sun and the moon phases - the civil or mobile calendar - and another based on the heliacal rising of Sirius the sothiac or fixed calendar. However, regardless of some issues that may still remain open about the coordination between the two systems (as the mismatch between the astronomical cycles and the fraction of $1 / 4$ in surplus that the solar year of 365 days has), based on astronomical documents relying on Sirius and Orion - the male counterpart of Sirius ${ }^{21}-$ on various astral personifications and even on non-astronomical texts, the pharaonic calendar assembled the cycles of the sun, moon and Sirius in a single system, a "great year» of 1461 years. Instead of abolishing the civil counting, this system required its maintenance, since the delay of a day each four years, in relation to the astral time, was annulled only after a 1461 years-period, the so-called «sothiac period $»^{22}$.

Among all stars, Sirius is closer to the tropical solar year: 365.2500 days for the 365.2422 days of the latter. To keep the sothiac calendar along with the lunar calendar, an additional day should be introduced every four years. This procedure prevents the two calenders - the sothiac and the lunar - from evolving independently. Both systems were set after a cycle completed every 1460 years.

Note that both calendars share the same number of units: a small one (the lunar calendar) is composed of four years with 365 days each, plus one day, totaling 1461 days, and a large one (the sthiac calendar) composed of four cycles of 365 years plus one year, making 1461 years.

This dual calendar provided a solid ground both for the technical operations revolving around the reckoning of time, but also for the development of a broader vision for the evolution of time itself. This system didn't have leap years, but the delay of a day every four years, got null after 1461 years $^{23}$. Since, because of its movement, the Earth takes the same position in each time of the year, the sothiac year was directly related to the seasons. But if one sothiac year is the time that elapses between two heliacal risings in the same latitude reference, it should be known which reference it was taken for such measurement because the heliacal rising varies with latitude. In ancient Egypt, it would probably be Buto, in the Western Delta.

To clear this question, the small ivory plate of Horus Djer (second or third king of Dynasty I about 3000 B.C.) found in Abydos is of major importance (Fig. 2). In a still very

\footnotetext{
${ }^{20}$ As the conjunction between terrestrial and celestial phenomena was only possible after long observations and data records, the tutelary deities of time and calendar could only be the divine pair Thoth, god of wisdom, writing and moon, and Seshat, goddess of writing and measurement.

${ }^{21}$ Sirius and Orion always appear together in a central position in the representations of the sothiac calendar.

${ }^{22}$ SALES, 2001: 166.

${ }^{23}$ BOMHARD, 1999: 28-30.
} 


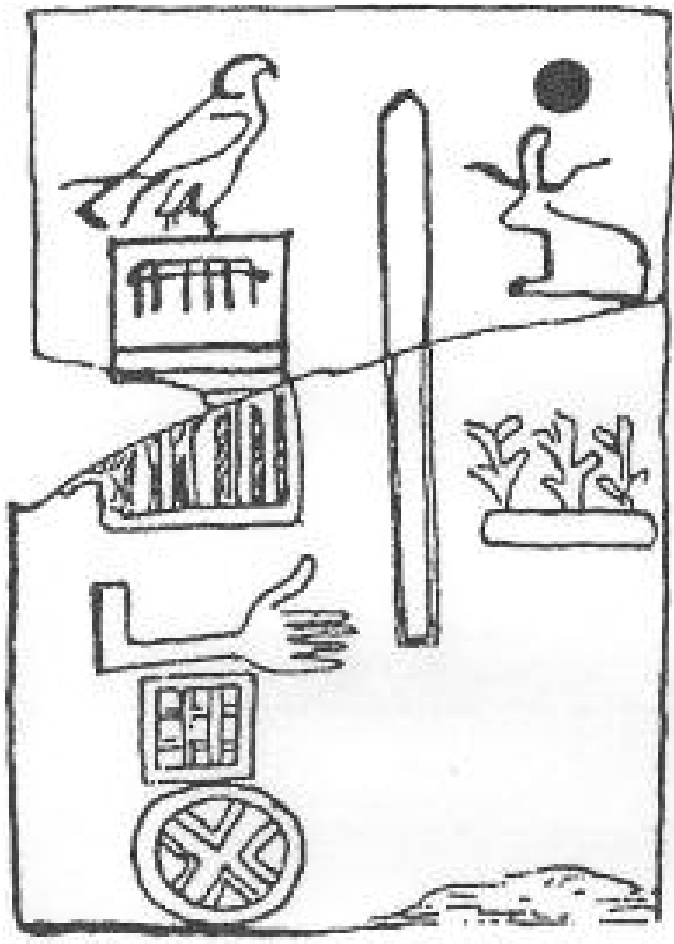

Fig. 2: A tablet of Horus Djer, about 3000 B.C., Abydos.

primitive hieroglyphic writing, its reading has received different interpretations. We share the opinion of those who think that it establishes the relationship between the appearance of Sirius and the beginning of the flood, and the reference to the name of Buto is considered to be a possible testimony for the antiquity of the establishment of the dual calendar. The plate presents two columns of text facing the center of the composition where stands an obelisk (tekhen), a «sun ray» considered sacred since at least from the 1st Dynasty on and probably evoking the solar manifestation of the king. On the left, top to bottom, figures a serek $h^{24}$ reading Hor djer Dep, «Horus the one who helps Dep (Buto)» or «Horus who ends [hunger] in Dep». On the right, we have the inscription su sepedet Akhet, literally «the day the floods rose with Sirius», ie, «the opening-of-the-year». The representation of Sirius taking form of a cow is not unique ${ }^{25}$, and it is probably associated with the concept of the «Cow of Heaven», the «nurturer» and protector of the Pharaoh and Egypt, a syncretic figure that may appear as Isis, Hathor, Sekhmet, or Sothis Sekhathor. The feather on the cow's horns has connotations with the cyclic return of the flood ${ }^{26}$ and it often appears in astronomical compositions as part of the headdress of Sothis, usually composed of a solar disk. Moreover, Buto fills the geographic (latitude) and historical (antiquity) conditions required to the sothiac eleva$\operatorname{tion}^{27}$.

The sothiac cycle was also the starting point for trying to date more precisely the establishment of the calendar. As in the year 139, during the reign of Roman emperor Antoninus Pius (138-161), the heliacal rising coincided with the first day of our present day calendar. Successive subtractions of periods of 1461 years, reach first the year 1322 B.C. at

\footnotetext{
${ }^{24}$ The serekh is a hieroglyphic symbol representing the façade of the palace where the Horus Name of the king was inscribed, and usually surmounted by a hawk, illustrating the concept of «Horus is in the palace».

${ }^{25}$ A similar depiction also appears in a relief at the entrance of the hypostyle hall at temple of Dendera.

${ }^{26}$ In this case it figures as the symbol of Shu evokink his journey to Nubia to bring the flood back to Egypt.

${ }^{27}$ BOMHARD, 1999: 46-49.
} 
the beginning of the 19th Dynasty (New Kingdom), then 2783 B.C., in the 2nd Dynasty (Early Dynastic Period), and 4244 B.C. (late Neolithic or early Predynastic Period), which, in the Lower Egypt, corresponded to the cultures of Merimde and Omari, in the Middle Egypt to the culture of the Fayum and, in the Upper Egypt to the culture of Tasa ${ }^{28}$.

Despite a certain mismatch between them, the Egyptians maintained their two calendars functional, the mobile and the fixed. The occasional references of this event in documents show that the sothiac year never supplanted the civil year in administrative contexts. On the other hand, they were aware of the disadvantages of using the mobile year, which was considered to be «bad», incorrect, as opposed to the «good», correct one. Even so, the later never replaced the fixed year, which was used as an obligation. This was contrary to their theology and rituals, in particular to what concerns the solar cult which found no reflection on the nature of the civil calendar. But this contradiction is only apparent. The use of the mobile year was imperative, since the functioning of the calendar was grounded on two essential facts: the rising of Sirius and the adjustment of the sothiac year. To this end, the star Sirius was always the crucial element.

Although the sothiac period was already known to classical authors, only after Champollion had deciphered the hieroglyphics could such information be confirmed in the Egyptian sources. The Papyrus Ebers is the only manuscript presenting a sothiac date and a list of festivals indexed to a mobile year - in this case the ninth year of the reign of Amenhotep I (Amenophis I) ${ }^{29}$. Other documents, such as the Stone of Elephantine, the Letter of Kahun, the Calendar of Medinet Habu or the Stele of Buto, keep important records to enlight this issue. Other sources (usually found in royal tombs and funerary temples) combine information related to the planets, Sirius and the lunar deities ${ }^{30}$.

Especially important for the study of the calendar are two astronomical compositions that figure in the Clepsydra of Karnak (Fig. 3), in a circular layout ${ }^{31}$, and in the Astronomical Ceiling of the Ramesseum (Fig. 4) in a horizontal layout ${ }^{32}$. Both were organized in three horizontal registers:

- Sirius figures in the upper register, with the decans and the planets (register II in the Ramesseum) thus evoking the sothiac cycle comprising the decans and the planets);

\footnotetext{
${ }^{28}$ RACHET, 1987: 59. If some accept that older date as a starting point of the calendar, others based on the idea that the year originally developed from the lunar calendar, have it as unacceptable. They go back about a thousand years, to approximately 3400 B.C., and attribute their invention to Heliopolitan priests, at a time when Heliopolis was supposedly the capital of a local unified kingdom at the end of the Predynastic Period, before or at the time of the probable unification of Narmer, and therefore at the time of Horus Djer or close to it.

${ }^{29}$ RACHET, 1987: 31-33.

${ }^{30}$ These depictions evoke the solar, stellar and cosmic destiny of the king. Dating varies from the 8th Dynasty to the Late Period.

${ }^{31}$ RACHET, 1987: 15-17.

${ }^{32}$ RACHET, 1987: 84-85.
} 


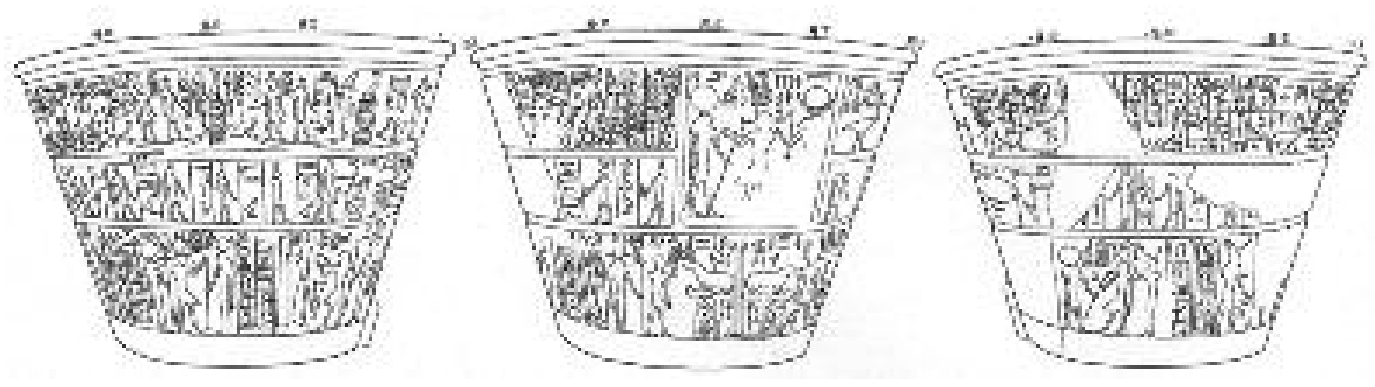

Fig. 3: The waterclock of Karnak, dating from the time of Amenhotep III (1402-1364 B.C.).

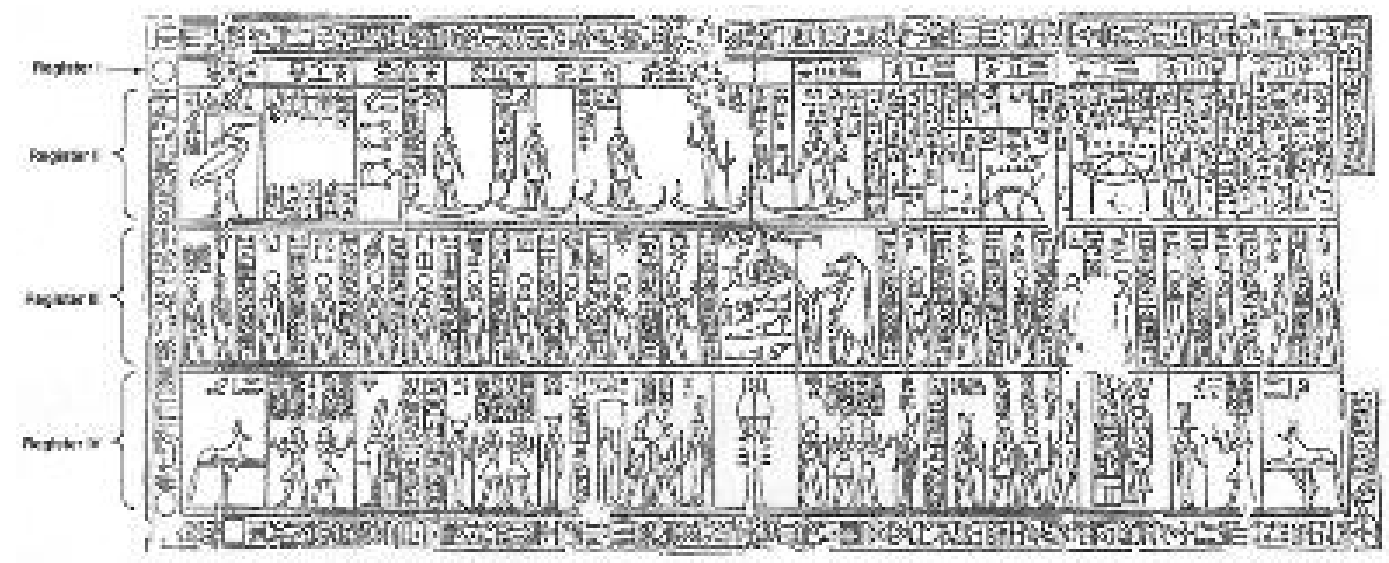

Fig. 4: Horizontal disposal of the astronomical cycles on the ceiling of the Ramesseum (1279-1213 B.C.).

- the second register presents the constellations of the northern sky and lunar deities (register III in the Ramesseum) thus alluding to the lunar year and monthly cycles);

- the lower register figures the pharaoh, sometimes assimilated to the solar deity, honoring the deities representing the months (register IV in the Ramesseum): the Pharaoh celebrating the deities of the twelve festivals evokes year divided into twelve months).

Most representations include only the first two records. In the Ramesseum there is also another one, register I, depicting the mobile year to which all cycles report to.

Presenting themselves at the center of the upper register (register II in the Ramesseum), the depiction of Orion and Sirius seem to dominate the whole composition. The later is placed on a boat personified in the goddess Isis, as indicated by the name inscribed there: Isis ( $₫)$ Sopdet $(\llbracket)$; in front, also standing on a boat, figures the deified (Sah Orion $(\mathbb{1 4 1 9})$, adorned with the three stars that compose this constellation. Regardless of small dif- 
ferences between documents, Sirius and Orion face the progression of the decans, but Orion has the body turned backwards, to Isis, as if to meet her. This position evidences the limit of the periods, the separation of the annual cycles: while Orion announces the end of the preceding year, Isis-Sirius opens the New Year.

Although the Egyptians had a proper term for the planet (guenemu), they commonly used the term seba both for star and planet (which prevents us from using this term with the restricted meaning of star), although they distinguished them: the 36 decanal stars were one entity and the planets were another, set aside with the epagomenal days, both located in the upper register, in the representations of the two registers. In pharaonic times, five planets visible to the naked eye were identified.
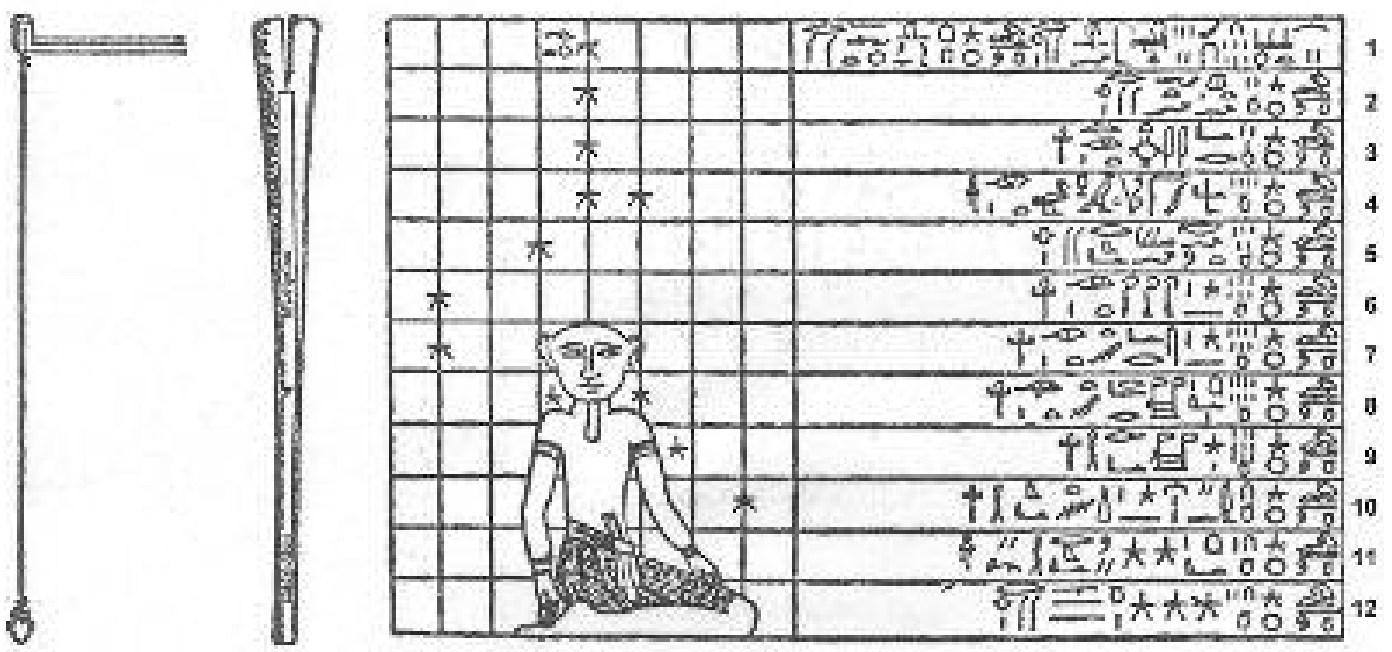

A

B

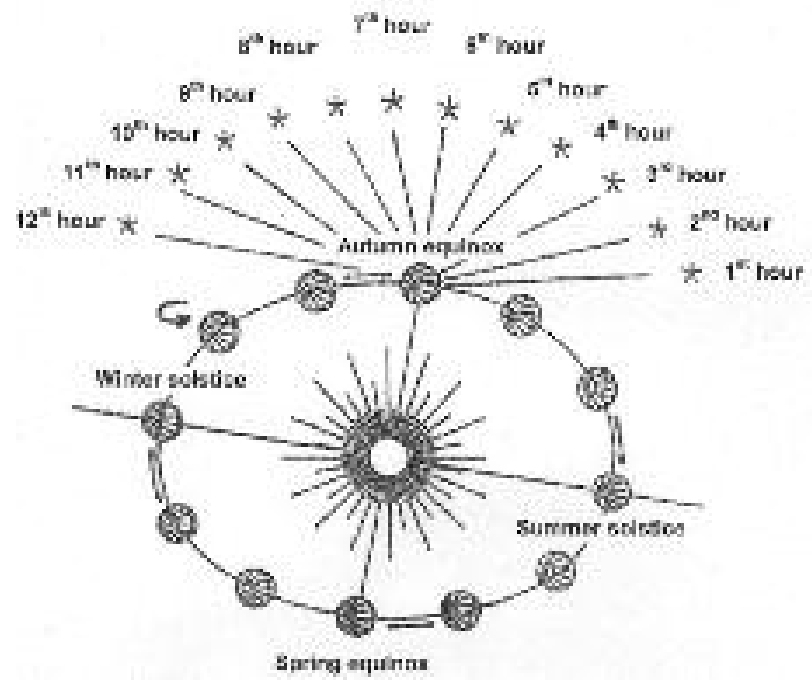

Fig. 5: Rotation: the twelve decans visible each night. Due to the rotation movement of the Earth, each of them indicates one hour of the night. At the equinoxes, each night hour is equal to the 24th part of the day.

Fig. 6: Stellar clocks: the merkhet (A), the sighting tool (B) and the astronomical table (stars list of the sixteenth day of month Paneipet, the second month of Akhet). 
Considering their orbits, they were grouped into internal, Mercury and Venus (sebeg and djai-Bennu) and external, Mars, Jupiter and Saturn (hor dechre, seba-resi and hor-ka pet) ${ }^{33}$. These two groups were represented in epagomenal days.

In the lower register of these compositions figures the moon, the monthly cycle and the lunar year. The ceiling of some tombs, like Senenmut's and Seti I's, show the lunar deities arranged, oriented and integrated with the other represented elements. Each lunar cycle lasts about 29 days and a half, and each phase of the moon, which is identified with a special festival, has its own designation: New Moon - pechedjenetiu, Crescent - shenet, Full Moon - shemedt and Last Quarter - denit. The days of the ascending phase of the moon are represented by a ladder of fourteen steps, also rising, each step containing one of the gods of the Great Ennead of Karnak. At the top, Thoth holds the udjat-eye the symbol both for the restored eye of Horus and the full moon ${ }^{34}$.

Apparently, the Egyptians had already understood by observing the movement of the planets and the determination of the periods of their synodic revolution, that the position of one or more planets repeated periodically thus allowing the construction of a dating system. However, there's a question to clarify: Egyptian astronomy, dominated by a priestly elite, was basically a science of religious character that had concerns of a practical nature, which in addition to measuring the time and the beginning of the flood, allowed, for example, the correct orientation of temples and tombs, according to their religious principles. However, it never achieved the brilliance of the astronomy of the Babylonians. Although the Egyptians could determine the North Pole with precision as well as its variation over the years, distinguish the visible planets without the aid of any tool, observe eclipses, realize the existence of meteors and follow a bright celestial body, probably comet Halley ${ }^{35}$, they were unable to develop scientific explanations for these astronomical phenomena. Despite the good set of observations required for all this, the Egyptian astronomy, as a whole, remained fairly rudimentary.

\section{CALENDAR AND MAGIC}

Based on mythic events or grounded on religious festivals, the Egyptians developed a series of superstitions associated with the calendar, which determined or forbade certain tasks on specific days. Although they were typical of the peoples of Antiquity, it was in Classical Antiquity that these ideas were widely spread, the Latin words fastu and nefastu being used respectively to designate the favorable days and the unfavorable days. While privately oracles and augurs could predict the future of a particular individual, the Julian calendar

\footnotetext{
${ }^{33}$ RACHET, 1987: 72-74.

${ }^{34}$ BOMHARD, 1999: 78-79.

${ }^{35}$ SAUNERON, 1970: 30.
} 
established general guidelines for the public life: of its 365 days, 188 were favorable meeting days (favorable to hold public meetings), 39 were simply favorable days, while 132 were unfavorable or holidays (not conducive to public business or mourning) and 16 were mixed, or partially unfavorable and partly favorable (as Saturdays when people only worked in the morning).

However, this Roman practice was already a reality in ancient Egypt. Several papyri, especially from the New Kingdom, list the thirty days of a month or even all the days of one year, including for each single day the designation of «good», «bad» or both "good and bad». For example, Mechir 1 - when the sky was created - or Athir 27 - the day when Horus and Seth made peace among themselves and decided to share the world - were considered favorable days. The unfavorable days were much fewer than the favorable. One of them was the fourteenth day of Tibi, when Isis and Nephthys wept over Osiris.

Other days that were not entirely bad, but were dangerous because they were exposed to particular threats, such as Khoiak 17 and 27: according to the time of the day, those days could be either good or bad. Favorable days did not require special precautions which of course were taken seriously to face unfavorable or dangerous days. For example, on Tibi 12 the eye couldn't stare on a mouse, which in Ancient Egypt was not by all means impossible; in relation to the day when Isis and Nephthys wept over Osiris, Tibi 14, one should prevent from singing or even to listen to music, on Tibi 16 one should not wash oneself, and on Farmuti 24 one should avoid uttering the name of Seth. There were other days - and they were many - when one should not do anything or leave home. In the month of Paofi only, there were four days to avoid any occupation and five others in which one should stay at home all day or at least part of it. Similar situations occurred in the remaining months. In such a scenario, the birth of a child was blessed or cursed, depending on being born on a lucky or unlucky day. For example, if the birth occurred on Khoiak 20, the child would be blind; if it was on Khoiak 3 the child would be deaf. The difficulty for the mother was to determine the right day to give birth! However, we should keep in mind that for the Egyptians superstition was important, as they believed that certain words or actions influenced both the forces of nature and the living creatures - from the smallest animal to the gods - they ruled their whole life by these beliefs ${ }^{36}$.

\section{THE HELLENIZATION OF THE EGYPTIAN CALENDAR}

On settling in Egypt, the Greeks did not see great benefit in maintaining the cosmic calendar, since the mobile calendar, the sun, was quite misaligned. They sought rather to create a mechanism not only to correct this misalignment, but also to avoid it from then

\footnotetext{
${ }^{36}$ ERMAN, RANKE, 1976: 453-454.
} 
on. The drift of one day every four years between the two calendars, thus causing the difference of one month in the beginning of the year every 120 years, led Ptolemy III Euergetes I (246-221 B.C.) to try to resolve the issue by decree (Decree of Canopus, from 238 B.C.), adjusting to the mobile year a sixth epagomenal day every four years. But changing the divine law of Thoth was not easy for the Ptolemies. Only in 25 B.C., with the Romans, was the leap year introduced by Augustus. Anyway, the chosen day was not the one of the Ptolemaic decree - the day when Sirius rose - but the first day of the month of Thoth in the mobile calendar - which in the year of the reform was 41 days after the heliacal rise. With this inclusion, the former mobile year became fixed, and Egyptians started to have two fixed calendars: the sothiac calendar - which started with the appearance of the star Sirius - and the Alexandrian calendar - beginning on the first day of Thoth, 41 days after the rise of Sirius.

The acceptance of this amendment at this time was due, certainly, to the existence of another calendar in Egypt, a solar calendar of 365.25 days to include the leap year: the former Julian calendar, introduced in the Roman empire by Julius Caesar in 45 B.C. The small difference from the actual length of the solar revolution (365.2422 days), would lead Pope Gregory XIII to fix it in 1582, removing the accumulated difference of ten days ahead of the official date (after October 4, 1582 came October 15, 1582). The error was avoided by introducing the rule that only the years ending in zero that were multiples of 400 would be leap years. The Gregorian reform has not only set the present day calendar but has its roots deeply steeped in ancient Egypt ${ }^{37}$.

The Egyptian calendar was clearly decanal, having star Sirius as the dominant and central element of astronomical representations, around which the civil year was organized, since always the most common year, in a system that included natural methods of self-regulation of astronomical cycles. The equinoctial hour itself was defined according to the length of the year: a new decan appeared every ten days and its revolution advanced one degree a day completing in 360 days. Twelve groups of three decades were the twelve months that coincided with the lunar cycles, adjusting the epagomenal days so that the mobile year could have 365 days. The quarter of day missing was recorded annually in each rise of Sirius, being the day thus generated every four years, diluted. The adjustment between the civil and the sothiac years was done in periods of 1461 years. In fact, a vertical axial reading of the Ramesseum, shows us Sirius as the basis of the system, inaugurating the sothiac year, the sothiac cycle, the decanal cycle and the lunar year, being its accuracy, stability and continuity symbolized by Thoth sitting on a pillar djed, whose four steps evoke the sothiac tetrarchy. The Egyptian calendar was designed as a true work of eternity.

The combination of these various elements, allows the parallelism between the different calendars, including the one we use today. Not only documents - such as Papyrus Ebers

${ }^{37}$ CANHÃO, 2006: 58-59. 
- highlight the relationship between the mobile and the fixed year of the Egyptians, but also certain astronomical events, such as equinoxes or heliacal rising, allow fixed references to any calendar. So you can say that to the third month of summer of the Egyptian mobile calendar corresponded the month of the New Year Festival on their fixed calendar; this began on the first day of Thoth, which corresponded to July 19 of the Julian calendar, corresponding to June 15 of our current calendar, at the latitude of Memphis. It is evident that the establishment of the Egyptian chronology is complex and those other elements besides astronomy must be considered: royal lists, historical texts, biographical records, dates of lunar Egyptian festivals, matching lists of Mesopotamian and Hebrew kings... However, none of this prevents many experts from considering the Egyptian calendar as the bedrock of the one that is used currently with a universal character, as the more rational, organized and clear of all that have been created throughout history.

\section{Figures acknowledgements:}

Figures 1, 2, 3, 4 and 5 adapted from Le calendrier égyptien. Une œuvre d'éternité, respectively from pages 65, 48, 16-17, 18-19 and 65; Figure 6 adapted from La civilisation égyptienne, pages 449-450 . 